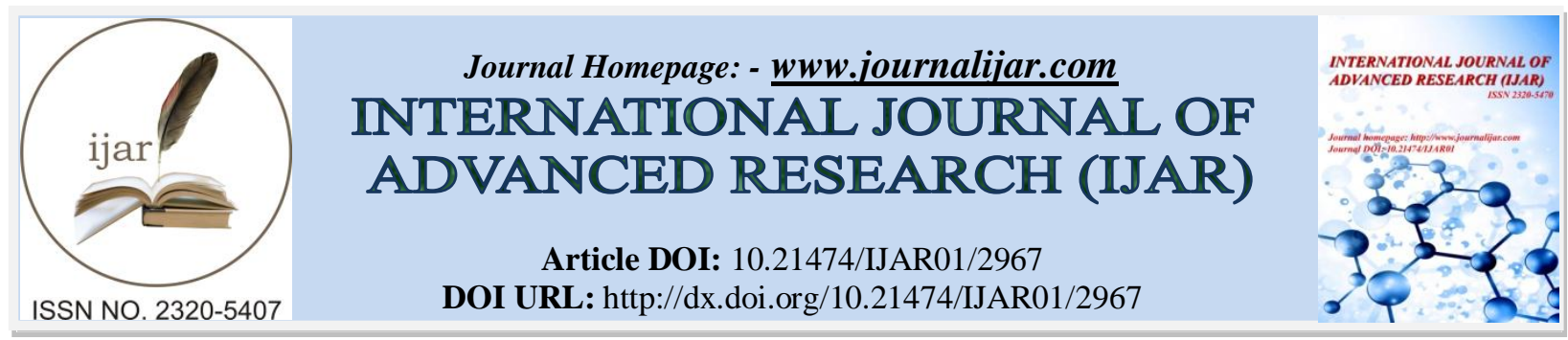

RESEARCH ARTICLE

\title{
BIOMETHANIZATION OF OLIVE MILL SOLID WASTE WITH TURKEY MANURE AT MESOPHILIC CONDITIONS
}

Tarek A. El-bashiti ${ }^{1 *}$, Mohamed M. Jouda ${ }^{2}$ and Mahmoud Alajouz ${ }^{3}$.

1. Department of Biology \& Biotechnology, The Islamic University-Gaza.

2. College of Intermediate Studies, Al-Azhar University-Gaza.

3. Agriculture Department, Al-Azhar University-Gaza.

\section{Manuscript Info}

\section{Manuscript History}

Received: 30 November 2016

Final Accepted: 26 December 2016

Published: January 2017

\section{Key words:-}

Anaerobic digestion, Biomethanization, Biogas, OMSW, Animal wastes, Turkey waste.

\begin{abstract}
Biomethanization or biogas production from olive mill solid waste (OMSW) attempted by co-digestion with Turkey manure at mesophilic conditions. A series of laboratory experiments were performed in anaerobic batch operating reactors, fed with mixtures of OMSW and Turkey manure at various concentrations. Anaerobic co-digestion is well-established process for treating solid organic wastes evaluated for biogas (methane) production.

The biogas production and some biochemical parameters of anaerobic digestion at $30^{\circ} \mathrm{C}$ for 40 days were studied as affected by two factors: (a) The type of the animal waste. (b) The ratio of animal waste to OMSW that constitute four levels (100:0 for P1; 80:20 for P2; 60:40 for P3 and 40:60 for P4) of 8\%total solid.

The total volume of biogas production at P1 was $(6247 \mathrm{ml})$, P2 (4316ml), P3 (1847ml) \& P4 (1613ml). The results indicated that there was a gradual decrease in total gas production in the digester by increasing the OMSW ratio, and the highest production was in the first week of the experiments in all digesters.
\end{abstract}

Copy Right, IJAR, 2016,. All rights reserved.

\section{Introduction:-}

Animal and agricultural wastes constitute a high proportion of biomass and their utilization and recycling is important for economic and environmental aspects. Anaerobic digestion one of the most widely used processes for treating these wastes and represents an attractive method for treating organic wastes for biogas production as alternative energy sources (Marques, 2001).

The two phases olive oil extraction process is the most important technology for olive oil production. In this technology, the olive paste is separated into two phases: olive oil and wet pomace or olive mill solid waste (OMSW). The OMSW is a semi-solid by-product composed by olive husk, olive pulp and olive vegetation water, which is usually reprocessed to further extract the residual oil increasing oil yields (Demerche et al., 2013)

OMSW represents poor agricultural residues that cannot be used alone for ruminant nutrition because it has high amounts of lignocellulosic materials that have low digestibility (Al-Masri, 2012). On the other hand, the other wastes such as Turkey manure are different because it already hydrolyzed but is considered as a source of mixed

Corresponding Author:- Tarek A. El-bashiti.

Address:-P.O.Box 108, Department of Biology \& Biotechnology, The Islamic University-Gaza. 
microbial culture that can be used in anaerobic digestion. These raw materials alone do not give specific applications up to date.

However, their elimination, mostly by burning, is the cause of various environmental problems (pollution and fires). The large volumes of OMSW generated in Gaza Strip pose important environmental problems such as aquifer contamination, eutrophication, undesirable smells, etc. (Tortosa et al., 2012 and 2014). However, OMSW in addition to animal wastes can be used as a source of fermentable organic matter in biomass technologies for gas production in a biomethanization process (El-Bashiti, 2010; Rodriguez-Gutierrez et al., 2012).

While some of the manure can be used as fertilizer, not all of it can be consumed in this way and the excess is an environmental liability. Another possibility is to use the manure as a direct or indirect source of fuel for remote power generation, avoids the cost of disposal, reduces odor and other nuisances associated with large livestock and poultry operations. The potential applications of the energy-from-manure concept include space heating, steam, and electricity (Ahn and Smith, 2008;Serio, 2002; Ro et al, 2010).

Because of lack of natural gas resources in Gaza Strip as a result of Israeli siege. Therefore, our goal of this research was to find a natural alternative. The alternative solution is to produce biogas from the natural resources, which can be available in Gaza Strip such as OMSW and animal manure as a source of digester culture.

\section{Materials and Method:- \\ Materials:-}

Turkey waste was collected from a farm at Rafah city in the south of Gaza Strip. OMSW was collected as byproduct of olive production. Both Turkey manure and OMSW were dried at room temperature. The OMSW was ground and sieved by $0.2 \mathrm{~cm}$ sieves size.

\section{Method:-}

Four digesters were prepared with four different Turkey waste and OMSW ratios P1, P2, P3, P4 as described in Table (1). Each digester was filled by tap water to 1 liter. The $\mathrm{pH}$ was adjusted at 7 and electric conductivity(E.C) was measured by sharp electric conductivity water proof (Table 2 ).

Then the digesters were kept at $30{ }^{\circ} \mathrm{C}$ in water bath for 40 days. The released biogas was collected in the graduated cylinders by water displacement (Figure 1\&2). At the end, the final pH and E.C were measured.

Table 1:- Anaerobic digester of different ratios of Turkey waste to OMSW

\begin{tabular}{|c|c|c|c|}
\hline Digester & Turkey waste/ OMSW (\%) & OMSW (g) & Turkey waste (g) \\
\hline P1 & $100 / 0$ & 0 & 80 \\
\hline P2 & $80 / 20$ & 16 & 64 \\
\hline P3 & $60 / 40$ & 32 & 48 \\
\hline P4 & $40 / 60$ & 48 & 32 \\
\hline
\end{tabular}

Table 2:- $\mathrm{pH}$ was adjusted at 7 and electric conductivity (E.C) values at the beginning of the experiments.

\begin{tabular}{|c|c|c|c|}
\hline Digester & Turkey waste/ OMSW(ratio) & E.C (m.s) & pH \\
\hline P1 & $100 / 0$ & 6.9 & 7 \\
\hline P2 & $80 / 20$ & 6.1 & 7 \\
\hline P3 & $60 / 40$ & 6.25 & 7 \\
\hline P4 & $40 / 60$ & 5.5 & 7 \\
\hline
\end{tabular}




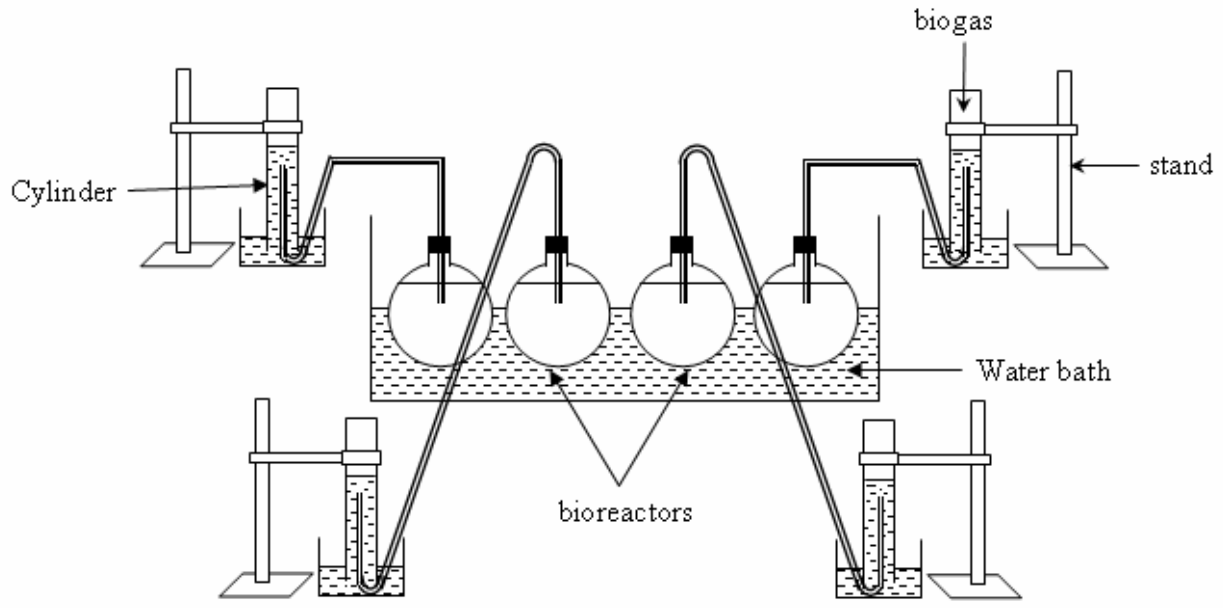

Figure 1:- The experimental set up of biogas production and collection.

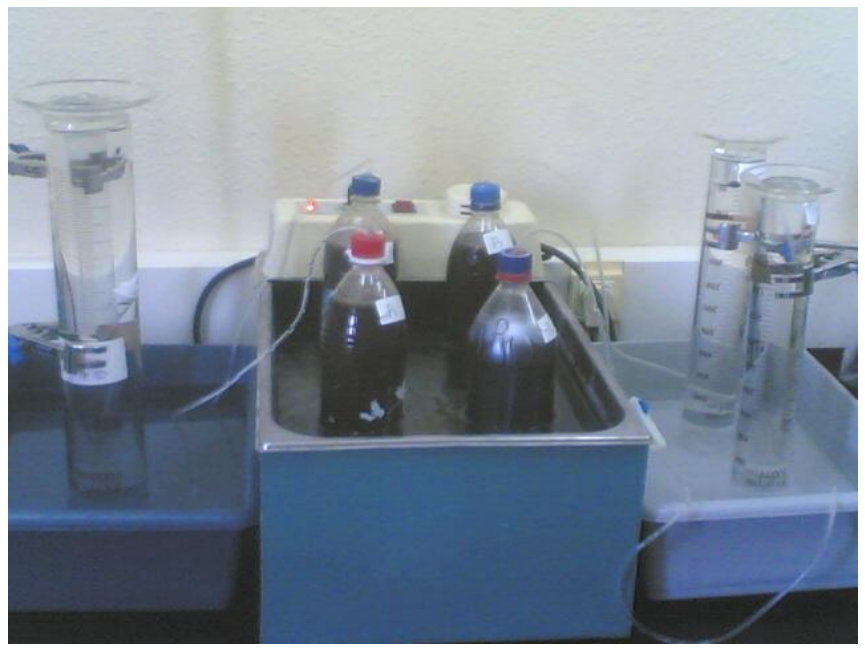

Figure 2:- The photograph of the experimental set up of biogas production and collection.

\section{Results:-}

As shown in Table 3 and Figure 3, P1 has the highest amount of total biogas production and the lowest amount was found at P4. The highest productivity of biogas was found in the first week by P1\&P2 (Figure 4).At the last week, P2 produces large amount of biogas when compared with the others (Figure 4). At the end of the fermentation process, we found the $\mathrm{PH}$ at the acidic range, and Electric conductivity was increased (Table 4).

Table 3:- Rate of biogas production within different time intervals and total biogas production of different ratios of Turkey wastes and OMSW.

\begin{tabular}{|c|c|c|c|c|c|c|c|c|c|c|c|}
\hline \multirow{3}{*}{$\begin{array}{c}\text { Turkey } \\
\text { wastel } \\
\text { OMSW } \\
\text { ratio of } \\
\text { total } 80 \mathrm{~g}\end{array}$} & \multicolumn{10}{|c|}{ Volume of Biogas (ml) } & \multirow{3}{*}{$\begin{array}{c}\text { Total } \\
\text { biogas } \\
\text { production } \\
(\mathbf{m l})\end{array}$} \\
\hline & \multicolumn{10}{|c|}{ Day } & \\
\hline & 1 & 2 & 3 & 4 & 5 & 6 & 7 & $8-21$ & $22-27$ & $27-40$ & \\
\hline P1(100/0) & 1000 & 730 & 1090 & 2200 & 1140 & 720 & 640 & 586 & 82 & 59 & 6247 \\
\hline $\mathrm{P} 2(\mathbf{8 0} / 20)$ & 1000 & 850 & 420 & 125 & 570 & \begin{tabular}{|l|}
70 \\
\end{tabular} & 20 & 53 & 59 & 1149 & 4316 \\
\hline$P 3(60 / 40)$ & $\mathbf{0}$ & 600 & 700 & 110 & 256 & $\mathbf{5 0}$ & 10 & 42 & 33 & 46 & 1847 \\
\hline P4(40/60) & $\mathbf{0}$ & 450 & 587 & 200 & 208 & 25 & 5 & 36 & 30 & 45 & 1613 \\
\hline
\end{tabular}




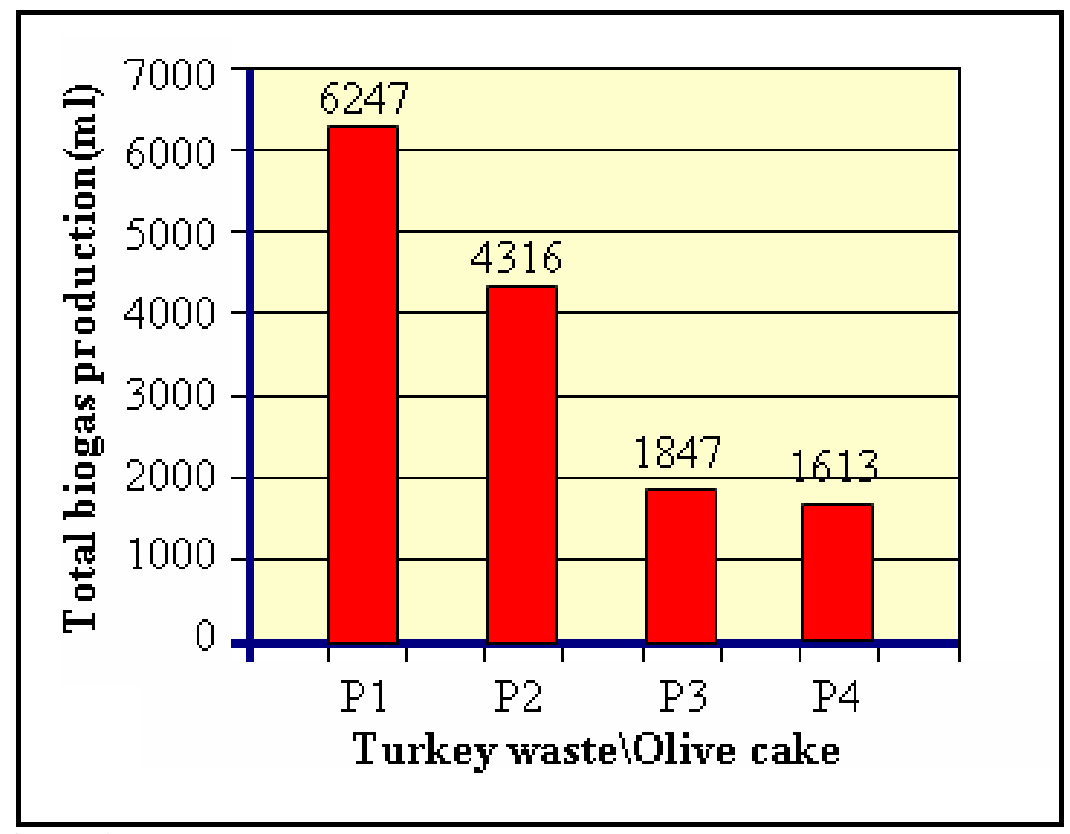

Figure 3:- Total biogas production $(\mathrm{ml})$ at the end of the fermentation process.

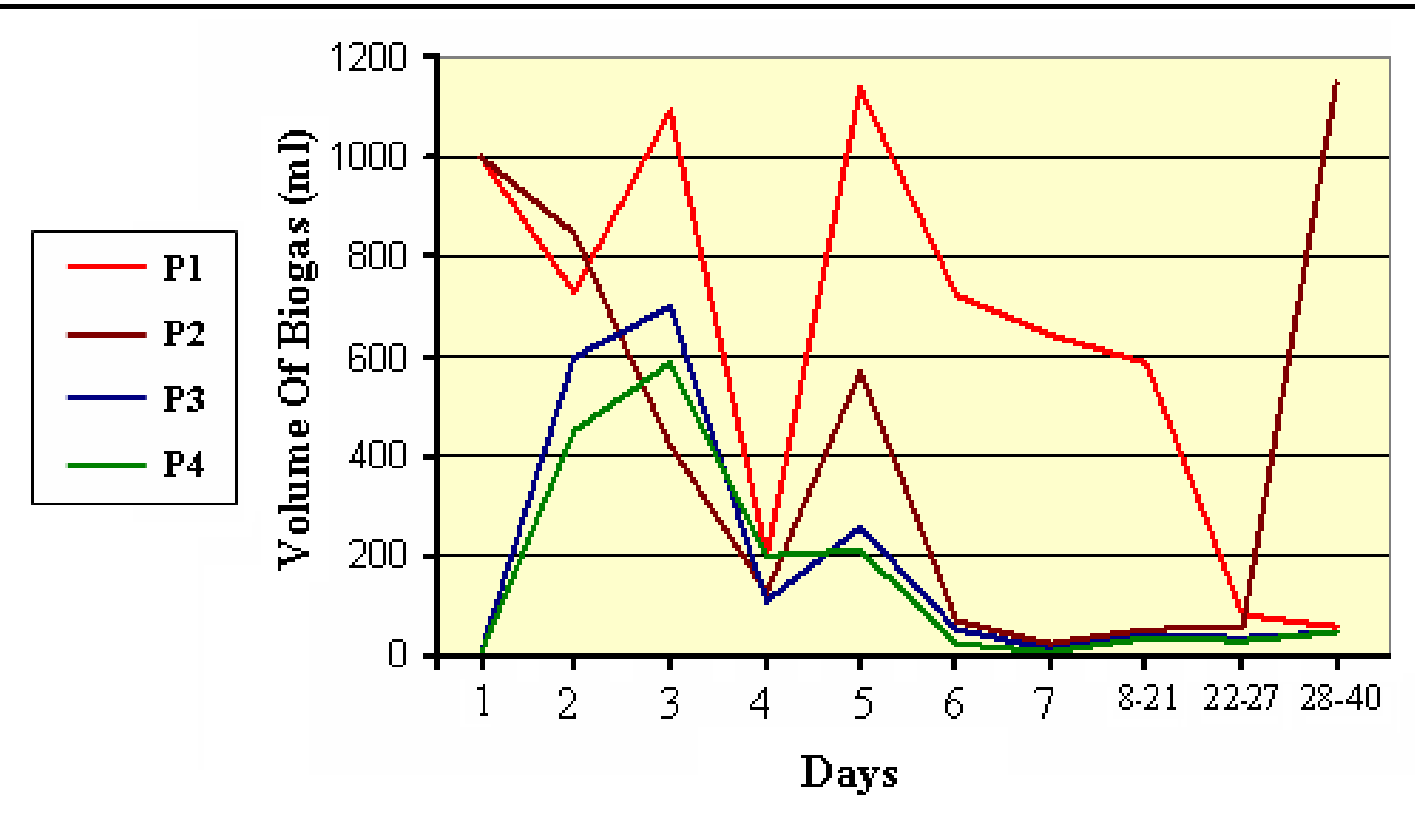

Figure 4:- Volume of biogas production during anaerobic fermentation (days).

Table 4:- The $\mathrm{pH}$ and electric conductivity at the end of fermentation process

\begin{tabular}{|c|c|c|}
\hline Reactor & pH (final) & E.C (final)m.s \\
\hline P1 & 4.98 & 14.73 \\
\hline P2 & 4.77 & 17.76 \\
\hline P3 & 4.73 & 13.83 \\
\hline P4 & 4.53 & 10.69 \\
\hline
\end{tabular}




\section{Discussion:-}

High production at $\mathrm{p} 1$ reefers to its Turkey content only as a digestive materials. The low product in other digesters refers to their contents of OMSW ratio. Percentage of biogas production is very low due to its content of high level of poly phenols (Battista et al, 2014), which considered as a toxic substances to the microorganisms.

Also, the late production of biogas is referring to the lignocellulosic compounds that constitute the major content of OMSW that increase the time of hydrolysis. Therefore, we needed to pretreatment of lignocellulosic materials to break it into simple components for easily digestion (Vintila et al, 2010).

The optimum pH for Anaerobic digestion is within a range of 6.8 to 8.0 (Ogiehor and Ovueni, 2014). More acidic or basic mixtures will ferment at a lower speed. Because the high amounts of dissolved $\mathrm{CO} 2$ can affect the pH (Dobre et al, 2014).Accumulation of volatile fatty acids (VFA) lead to imbalance in an anaerobic digester, which causes harp decrease in the $\mathrm{pH}$ (Acharya et al, 2011 and Zhang et al, 2015).

\section{Conclusion and Recommendation:-}

It was good idea as an alternative solution, to produce biogas from natural resources in order to provide a healthy product, which is friendly to environment, easy to produce, and available for common people. Thus, biomethanization or biogas production from OMSW and Turkey manure can be the most optimal method to fulfill our requirements for its safety, affordability, and availability in nature.

To be more beneficial and vital process, we strongly recommend pretreatment of the OMSW to help in degradation of the lignocellulosic materials before biomethanization process to increase the biogas productivity.

\section{References:-}

1. Acharya, B. K., Pathak, H., Mohana, S., Shouche, Y., Singh, V., \&Madamwar, D. (2011). Kinetic modelling and microbial community assessment of anaerobic biphasic fixed film bioreactor treating distillery spent wash. Water research, 45(14), 4248-4259.

2. Ahn, H. K., \& Smith, M. C. (2008). Biogas production potential from switch grass-animal manure mixture using dry anaerobic digestion. In 2008 Providence, Rhode Island, June 29-July 2, 2008 (p. 1). American Society of Agricultural and Biological Engineers.

3. Al-Masri, M. R. (2012). An in vitro nutritive evaluation of olive tree (Oleaeuropaea) pruning residues as affected by cutting regimen. Bioresource technology, 103(1), 234-238.

4. Battista, F., Fino, D., \& Ruggeri, B. (2014). Polyphenols concentration's effect on the biogas production by wastes derived from olive oil production. CHEMICAL ENGINEERING, 38.

5. Demerche, S., Nadour, M., Laroche, C., Moulti-Mati, F., Michaud, P. (2013) Olive mill wastes: Biochemical characterization and valorization strategies. Process Biochemistry, 48, 1532-1552.

6. Dobre, P., Nicolae, F. A. R. C. A. Ş., \& Matei, F. (2014). Main factors affecting biogas production-an overview. Romanian Biotechnological Letters, 19(3), 9283-9296.

7. El Bashiti, T. (2010). Biogas production by co digestion of animal. Journal of Al Azhar University-Gaza (ICBAS Special Issue), vol. 12, 27-30.

8. Marques, I.P.,"Anaerobic digestion treatment of olive mill wastewater for effluent re-use in irrigation", Desalination (2001), vol. 37, pp233-239.

9. Ogiehor I.S. and Ovueni U.J. (2014). Effect of temperature, pH, and solids concentration on biogas production from poultry waste. International Journal of Scientific \& Engineering Research, 5(1), 62-69.

10. Rodriguez-Gutierrez, G., Lama, A., Ruiz, M. V., Rubio, F., Fernandez-Bolanos, J. (2012) New olive pomace oil improved by hydrothermal pre-treatment. In: Olive oil-Constituents-Quality, Health Properties and Bioconversions. Edited by D. Boskou. Intech Europe, Rijeka, Croatia, 249-266.

11. Ro, K. S., Cantrell, K. B., \& Hunt, P. G. (2010). Pyrogasification of blended animal manures to produce combustable gas and biochar. In International Symposium on Air Quality and Manure Management for Agriculture Conference Proceedings, 13-16 September 2010, Dallas, Texas (p. 1). American Society of Agricultural and Biological Engineers.

12. Serio, M. A., Bassilakis, R., Kroo, E., \&Wójtowicz, M. A. (2002). Pyrolysis processing of animal manure to produce fuel gases. Fuel Chemistry Division Preprints, 47(2), 588. 
13. Tortosa, G., Alburquerque, J.A., Ait-Baddi,G., Cegarra, J. (2012) The production of commercial organic amendments and fertilizers by composting of two-phase olive mill waste (alperujo). Journal of Clean Production, 26, 48-55.

14. Tortosa, G., Alburquerque, J.A., Bedmar, E.J., Ait-Baddi,G., Cegarra, J. (2014) Strategies to produce commercial liquid organic fertilizers (alperujo) composts. Journal of Clean Production, 82, 37-44.

15. Vintila, T., Dragomirescu, M., Croitoriu, V. E. R. O. N. I. C. A., Vintila, C., Barbu, H. O. R. I. A., \& Sand, C. (2010). Saccharification of lignocellulose-with reference to Miscanthus-using different cellulases. Romanian Biotechnological Letters, 15(4), 5498.

16. Zhang, C., Su, H., Wang, Z., Tan, T., \& Qin, P. (2015). Biogas by semi-continuous anaerobic digestion of food waste. Applied biochemistry and biotechnology, 175(8), 3901-3914. 